\title{
Fabrication and Characterization of Magnetoresponsive Electrospun Nanocomposite Membranes Based on Methacrylic Random Copolymers and Magnetite Nanoparticles
}

\author{
Ioanna Savva, ${ }^{1}$ George Krekos, ${ }^{1}$ Alina Taculescu, ${ }^{2,3}$ Oana Marinica, ${ }^{4}$ \\ Ladislau Vekas, ${ }^{2}$ and Theodora Krasia-Christoforou ${ }^{1}$ \\ ${ }^{1}$ Department of Mechanical and Manufacturing Engineering, University of Cyprus, 75 Kallipoleos Avenue, 1678 Nicosia, Cyprus \\ ${ }^{2}$ Center for Fundamental and Advanced Technical Research, Romanian Academy, Timisoara Branch, Bd. Mihai Viteazul No. 24, \\ 1900 Timisoara, Romania \\ ${ }^{3}$ Faculty of Industrial Chemistry and Environmental Engineering, "Politehnica" University of Timisoara, P-ta Victoriei No. 2, \\ 300006 Timisoara, Romania \\ ${ }^{4}$ Research Center for Engineering of Systems with Complex Fluids, "Politehnica" University of Timisoara, P-ta Victoriei No. 2, \\ 300006 Timisoara, Romania
}

Correspondence should be addressed to Theodora Krasia-Christoforou, krasia@ucy.ac.cy

Received 23 January 2012; Accepted 1 February 2012

Academic Editor: Sevan P. Davtyan

Copyright (C) 2012 Ioanna Savva et al. This is an open access article distributed under the Creative Commons Attribution License, which permits unrestricted use, distribution, and reproduction in any medium, provided the original work is properly cited.

\begin{abstract}
Magnetoresponsive polymer-based fibrous nanocomposites belonging to the broad category of stimuli-responsive materials, is a relatively new class of "soft" composite materials, consisting of magnetic nanoparticles embedded within a polymeric fibrous matrix. The presence of an externally applied magnetic field influences the properties of these materials rendering them useful in numerous technological and biomedical applications including sensing, magnetic separation, catalysis and magnetic drug delivery. This study deals with the fabrication and characterization of magnetoresponsive nanocomposite fibrous membranes consisting of methacrylic random copolymers based on methyl methacrylate (MMA) and 2-(acetoacetoxy)ethyl methacrylate (AEMA) (MMAco-AEMA) and oleic acid-coated magnetite $\left(\mathrm{OA} \cdot \mathrm{Fe}_{3} \mathrm{O}_{4}\right)$ nanoparticles. The AEMA moieties containing $\beta$-ketoester side-chain functionalities were introduced for the first time in this type of materials, because of their inherent ability to bind effectively onto inorganic surfaces providing an improved stabilization. For membrane fabrication the electrospinning technique was employed and a series of nanocomposite membranes was prepared in which the polymer content was kept constant and only the inorganic $\left(\mathrm{OA} \cdot \mathrm{Fe}_{3} \mathrm{O}_{4}\right)$ content varied. Further to the characterization of these materials in regards to their morphology, composition and thermal properties, assessment of their magnetic characteristics disclosed tunable superparamagnetic behaviour at ambient temperature.
\end{abstract}

\section{Introduction}

In the last years, stimuli-responsive polymer-based membranes the properties of which can be externally triggered upon variation of the $\mathrm{pH}$, the temperature, and the magnetic or electrical field have attracted increasing attention due to their numerous potential applications, for example, in sensing technologies, in separation processes, and in the biomedical field such as controlled drug delivery systems [1].

One of the most versatile methods employed for generating polymeric (nano)fibrous membranes is electrospinning
$[2,3]$. With this method, fibrous mats are produced by electrically charging a suspended droplet of polymer melt or solution. Electrospinning exhibits the most demonstrating and promising results for numerous applications, because of its simplicity, versatility, low cost, and the ability to produce continuous (nano)fibers of various materials from polymers to ceramics to composites [4-6]. Moreover, it may provide control over the thickness and composition of the produced (nano)fibers along with the porosity of the (nano)fibrous mesh. The produced electrospun fibrous membranes, which usually consist of fibers having diameters from a few $\mathrm{nm}$ 
up to a few micrometers [7], are considered for a variety of applications, such as molecular filtration [8] catalysis [9] and electronics [10] in biomedicine as scaffolds for tissue engineering [11-13] and drug release carriers [14]. The large surface-to-volume ratio, the existing flexibility on the selection of the surface functionality, the interesting mechanical properties, and the freedom on materials' design $[15,16]$ are only a few characteristics that make the polymeric (nano)fibers and the resulting membranes ideal in the above-mentioned important applications.

A particular class of stimuli-responsive, nanocomposite polymer-based membranes is the so-called magnetoresponsive membranes. These materials consist of magnetic (nano)particles embedded within a polymeric membrane, and their properties are influenced by the presence of an externally applied magnetic field.

The electrospinning process has been successfully employed for the fabrication of magnetoresponsive fibrous membranes. Among the magnetic particles incorporated within such systems, magnetite $\left(\mathrm{Fe}_{3} \mathrm{O}_{4}\right)$ is by far the most commonly used [17-22]. Besides the above-mentioned systems, other reports include the fabrication of polymer composite membranes containing FePt [23], $\mathrm{CoFe}_{2} \mathrm{O}_{4}$ [24] and Fe [25] particles.

Herein, we describe the fabrication of magnetoresponsive fibrous membranes consisting of functional polymeric materials and oleic acid-coated magnetite $\left(\mathrm{OA} \cdot \mathrm{Fe}_{3} \mathrm{O}_{4}\right)$ nanoparticles. More precisely, random copolymers based on methyl methacrylate (MMA) and 2-(acetoacetoxy)ethyl methacrylate (AEMA) of the type MMA-co-AEMA have been prepared via conventional free radical polymerization.

The AEMA moieties containing $\beta$-ketoester side-chain functionalities were introduced because of their ability to bind effectively onto the inorganic iron oxide surfaces providing an improved stabilization. The latter has been demonstrated in recent publications of our group, reporting on the synthesis and characterization of well-defined hydrophilic diblock copolymers based on AEMA and hexa(ethylene glycol) methyl ether methacrylate (HEGMA) and their use as stabilizing agents for iron oxide nanoparticles [26] and single-wall carbon nanotubes $/ \mathrm{Fe}_{3} \mathrm{O}_{4}$ [27] in aqueous solutions. Moreover, we have also described the preparation of nanocomposite amphiphilic random conetworks exhibiting temperature- and magnetoresponsive behavior comprised of (HEGMA), AEMA, and $\mathrm{OA} \cdot \mathrm{Fe}_{3} \mathrm{O}_{4}$ nanoparticles [28].

The MMA-co-AEMA (code_IS) was mixed with preformed $\mathrm{OA} \cdot \mathrm{Fe}_{3} \mathrm{O}_{4}$ in tetrahydrofuran (THF) at appropriate polymer solution concentrations, and the solutions were electrospun under specific experimental conditions to yield fibrous nanocomposite magnetoresponsive membranes. The preference of incorporating preformed, oleic acid (OA)coated magnetite nanoparticles with mean diameters of around $4-5 \mathrm{~nm}$ within the conetworks, targeted toward the prevention of agglomeration phenomena, thus to obtaining a superparamagnetic response.

The fabricated membranes were characterized in terms of their morphology by scanning electron microscopy (SEM), whereas the presence of magnetite within the membranes was confirmed by X-ray diffraction (XRD) spectroscopy.
Their thermal properties were investigated employing thermal gravimetric analysis (TGA). These materials exhibited a superparamagnetic behavior and tunable magnetic properties at ambient temperature depending on the percentage of the magnetic content within the membranes, as demonstrated by vibrating sample magnetometry (VSM) measurements.

\section{Experimental Section}

2.1. Reagents and Materials. Ethyl acetate (EA) (Fluka, 99.8\%), tetrahydrofuran (THF) (Sharlau, HPLC grade), and n-hexane (Sharlau, 96\%) were used as received by the manufacturer. The two monomers methyl methacrylate (MMA) (99\%) and 2-(acetoacetoxy) ethyl methacrylate (AEMA) (95\%) were purchased from Sigma-Aldrich and used without further purification. The radical initiator $2,2^{\prime}$ azobis(isobutylnitrile) (AIBN, 95\%) was purchased from Sigma-Aldrich, and it was recrystallized twice from ethanol prior to use. Concerning deuterated solvents, deuterated chloroform $\mathrm{CDCl}_{3}$ (Sharlau) was used in ${ }^{1} \mathrm{H}$ NMR studies.

2.2. Synthesis of $\mathrm{OA} \cdot \mathrm{Fe}_{3} \mathrm{O}_{4}$-Coated Magnetic Nanoparticles. The oleic acid-coated magnetite nanoparticles $\left(\mathrm{OA} \cdot \mathrm{Fe}_{3} \mathrm{O}_{4}\right)$ were prepared by following an experimental procedure developed by Bica et al. [29-31]. Briefly, magnetite nanoparticles, $\mathrm{Fe}_{3} \mathrm{O}_{4}$, were obtained by the coprecipitation in an aqueous solution of $\mathrm{Fe}^{2+}$ and $\mathrm{Fe}^{3+}$ ions (salts $\mathrm{FeSO}_{4} \cdot 7 \mathrm{H}_{2} \mathrm{O}$; $\mathrm{FeCl}_{3} \cdot 4 \mathrm{H}_{2} \mathrm{O}$ ) in the presence of $\mathrm{NH}_{4} \mathrm{OH}$, at $80-82^{\circ} \mathrm{C}$. A temperature of $80^{\circ} \mathrm{C}$ set for the coprecipitation reaction is essential to obtain magnetite and no other iron oxides; the same temperature range is also favorable for the chemisorption of oleic acid on the surface of magnetite nanoparticles. Additionally, the significant excess amount of $\mathrm{NH}_{4} \mathrm{OH}$ ensures the formation of magnetite over other iron oxides. Subsequently, oleic acid was added in a significant excess (about $30 \mathrm{vol} \%$ ) to the system right after the coprecipitation had started, which resulted in the chemisorption of the acid on the magnetite surface. This was followed by a washing process with distilled water with magnetic decantation and filtration to remove aggregated (nondispersed) particles. Then, flocculation (acetone) was used to extract magnetite particles coated with a single surfactant layer from the solution of residual salts and free surfactant. The dried powder was redispersed in light hydrocarbon. This flocculation/redispersion procedure was performed several times to ensure that the presence of free surfactant in the final solution was negligible.

2.3. Synthesis of MMA-co-AEMA Random Copolymers. Conventional free radical polymerization was employed for the synthesis of the MMA-co-AEMA random copolymers. Polymerizations were carried out in a $50 \mathrm{~mL}$ round-bottom flask, fitted with a rubber septum. The monomers MMA $(2.1 \mathrm{~mL}, 19.6 \mathrm{mmol})$ and AEMA $(4.3 \mathrm{~mL}, 22.5 \mathrm{mmol})$ were transferred into the reaction flask with the aid of a syringe. THF $(21 \mathrm{~mL})$ was subsequently added followed by the 
TABLE 1: Quantities of the reactants used for the synthesis of a series of MMA-co-AEMA random copolymers.

\begin{tabular}{lccccccc}
\hline a/a & Sample code & MMA $(\mathrm{mL})$ & MMA $(\mathrm{mmol})$ & AEMA $(\mathrm{mL})$ & AEMA $(\mathrm{mmol})$ & AIBN $(\mathrm{mg})$ & Solvent* $(\mathrm{mL})$ \\
\hline 1 & IS1 & 2.0 & 18.7 & 4.3 & 22.5 & 65 & $20(\mathrm{EA})$ \\
2 & IS2 & 4.2 & 39.3 & 7.6 & 39.8 & 13 & $40(\mathrm{EA})$ \\
3 & IS3 & 8.4 & 78.5 & 7.6 & 39.8 & 17 & $54(\mathrm{EA})$ \\
4 & IS4 & 2.1 & 19.6 & 4.3 & 22.5 & 2.5 & $21(\mathrm{THF})$ \\
\hline
\end{tabular}

*EA: ethyl acetate; THF: tetrahydrofuran.

TABLE 2: Optimum experimental conditions successfully employed for the fabrication of MMA-co-AEMA fibrous membranes in absence and presence of $\mathrm{OA} \cdot \mathrm{Fe}_{3} \mathrm{O}_{4}$ nanoparticles.

\begin{tabular}{lccccc}
\hline a/a & Sample code & $\begin{array}{c}\text { Needle-to- } \\
\text { collector } \\
\text { distance }(\mathrm{cm})\end{array}$ & Needle $(\mathrm{G})$ & Voltage $(\mathrm{kV})$ & $\begin{array}{c}\text { Flow rate } \\
(\mu \mathrm{L} / \mathrm{min})\end{array}$ \\
\hline 1 & IS3 & 30 & 16 & 10 & 50 \\
2 & IS3.2 & 25 & 16 & 15 & 30 \\
3 & IS3.4 & 25 & 16 & 15 & 30 \\
4 & IS3.10 & 25 & 16 & 15 & 20 \\
\hline
\end{tabular}

addition of the initiator AIBN $\left(2.5 \mathrm{mg}, 1.52 \cdot 10^{-5} \mathrm{~mol}\right)$ dissolved in the solvent $(2 \mathrm{~mL})$. After dissolution, the reaction mixture was placed in an oil bath at $63^{\circ} \mathrm{C}$ for $20 \mathrm{~h}$ under inert (nitrogen) atmosphere. Polymerization was terminated by cooling the reaction down to room temperature. The produced MMA-co-AEMA random copolymer $(6.43 \mathrm{~g}$, 95\% polymerization yield) was retrieved by precipitation in $n-$ hexane (polymer solution to $n$-hexane in volume ratio $1: 10$ ) and was left to dry in vacuum at room temperature for a few hours. Table 1 summarizes the quantities of the reactants used for the synthesis of the MMA-co-AEMA random copolymers.

${ }^{1} \mathrm{H}$ NMR $\left(300 \mathrm{MHz}, \mathrm{CDCl}_{3}\right) \delta(\mathrm{ppm}): 4.1-4.5(\mathrm{br}, 4 \mathrm{H}(\mathrm{e}$, d)), $3.5(\mathrm{~m}, 5 \mathrm{H}(\mathrm{f}, \mathrm{b})), 2.3(\mathrm{~m}, \mathrm{br}, 3 \mathrm{H}(\mathrm{g})), 1.6-2.1$ (m, br, $4 \mathrm{H}\left(\mathrm{a}, \mathrm{a}^{\prime}\right)$, and 0.8 (s, br, $6 \mathrm{H}\left(\mathrm{c}, \mathrm{c}^{\prime}\right)$ ). (br: broad; s: singlet; $\mathrm{m}$ : multiplet).

2.4. Membrane Fabrication. The random copolymer IS3 was mixed with different amounts of $\mathrm{OA} \cdot \mathrm{Fe}_{3} \mathrm{O}_{4}(2,4,10,30$, and $70 \% \mathrm{w} / \mathrm{w}$ ) in THF solution at room temperature (samples IS3.2, IS3.4 and IS3.10, IS3.30, and IS3.70, resp.). In all cases, the polymer concentration was kept constant $(0.06 \mathrm{~g} / \mathrm{mL})$ and only the concentration of the $\mathrm{OA} \cdot \mathrm{Fe}_{3} \mathrm{O}_{4}$ varied. For assisting the dissolution of the $\mathrm{OA} \cdot \mathrm{Fe}_{3} \mathrm{O}_{4}$, all solutions were placed in an ultrasonic bath for $20 \mathrm{~min}$. Subsequently, they were filtered prior to electrospinning.

All electrospinning experiments were performed at room temperature. Equipment included a controlled-flow, fourchannel volumetric microdialysis pump (KD Scientific, Model: 789252), syringes with specially connected spinneret needle electrodes, a high-voltage power source $(10-50 \mathrm{kV})$ and custom-designed, grounded target collectors, inside an interlocked Faraday enclosure safety cabinet.

Systematic parametric studies were carried out by varying the applied voltage, the needle-to-collector distance, the needle diameter, and the flow rate so as to determine the optimum experimental conditions for obtaining fibrous membranes. Table 2 summarizes the experimental conditions employed successfully for the fabrication of MMA-coAEMA fibrous membranes both in absence and presence of $\mathrm{OA} \cdot \mathrm{Fe}_{3} \mathrm{O}_{4}$ nanoparticles.

2.5. Characterization. Proton nuclear magnetic resonance $\left({ }^{1} \mathrm{H}\right.$ NMR $)$ spectroscopy was used for confirming the expected structure of the copolymers. ${ }^{1} \mathrm{H}$ NMR spectra were recorded in $\mathrm{CDCl}_{3}$ using an Avance Brucker $300 \mathrm{MHz}$ spectrometer equipped with an ultrashield magnet. The $\mathrm{CDCl}_{3}$ contained traces of tetramethylsilane (TMS), which was used as an internal reference.

The average molecular weights and polydispersity indices of the copolymers were determined by size exclusion chromatography (SEC). All measurements were carried out at room temperature using Styragel HR 3 and Styragel HR 4 columns. The mobile phase was THF, delivered at a flow rate $1 \mathrm{~mL} \mathrm{~min}^{-1}$ using a Waters 515 isocratic pump. The refractive index was measured with a Waters 2414 refractive index detector. The instrumentation was calibrated using poly(methyl methacrylate) (PMMA) standards with narrow polydispersity indices (MWs of 102, 450, 670, 1580, 4200, 14400, 31000, 65000, 126000, 270000, 446000, $739000 \mathrm{~g} \mathrm{~mol}^{-1}$ ) supplied by Polymer Standards Service (PSS).

X-ray powder diffraction patterns were obtained using Rigaku $(30 \mathrm{kV}, 25 \mathrm{~mA})$ with $\lambda=1.5405 \AA(\mathrm{Cu})$ in the range of $20-80^{\circ}$ and at a scanning rate of $1^{\circ} / \mathrm{min}$.

Thermal gravimetric analysis (TGA) measurements were carried out with a SETARAM SETSYS 16/18 TG-DTA. Samples $(6 \pm 0.2 \mathrm{mg})$ were placed in alumina crucibles. An empty alumina crucible was used as a reference. Samples were heated from ambient temperature to $600^{\circ} \mathrm{C}$ in a $50 \mathrm{~mL} / \mathrm{min}$ flow of argon $(\mathrm{Ar})$ with heating rate $10^{\circ} \mathrm{C} / \mathrm{min}$ 


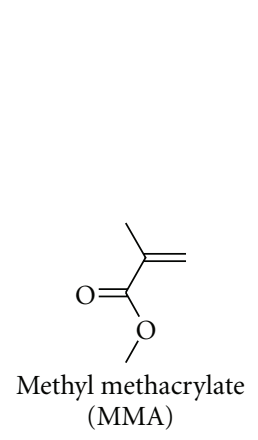

(a)

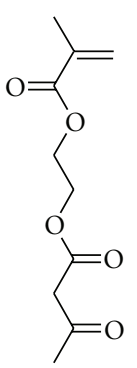

2-(acetoacetoxy)ethyl methacrylate (AEMA)

(b)<smiles>CC(C)(C#N)N=NC(C)(C)C#N</smiles>

$2,2^{\prime}$-azobis(isobutylnitrile)

(AIBN)
FIgURE 1: Chemical structures and names of the main reagents used for the synthesis of the MMA-co-AEMA random copolymers.

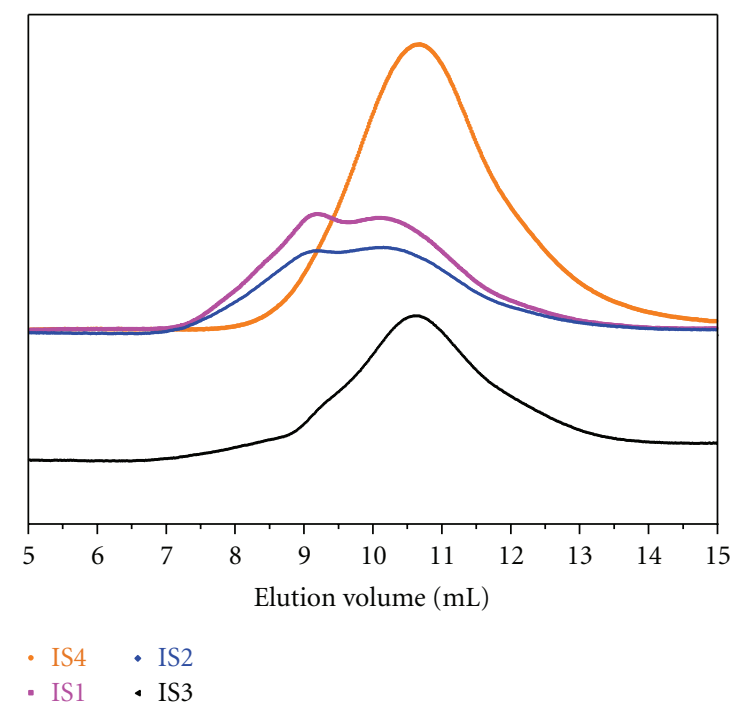

Figure 2: SEC eluograms of the MMA-co-AEMA random copolymers (IS1-IS4) prepared in this study.

and continuous records of sample temperature, sample weight, its first derivative and heat flow were taken.

The morphological characteristics of the fibrous membranes obtained in the absence and presence of $\mathrm{OA} \cdot \mathrm{Fe}_{3} \mathrm{O}_{4}$ nanoparticles were determined by scanning electron microscopy (SEM) (Vega TS5136LS-Tescan). The samples were gold-sputtered $(\sim 15 \mathrm{~nm})$ (sputtering system K575X Turbo Sputter Coater-Emitech) prior to SEM inspection.

Finally, the magnetic properties of the nanocomposite MMA-co-AEMA/OA- $\mathrm{Fe}_{3} \mathrm{O}_{4}$ fibrous membranes were measured with a vibrating sample magnetometer (VSM), Model 880 from ADE Technologies, USA.

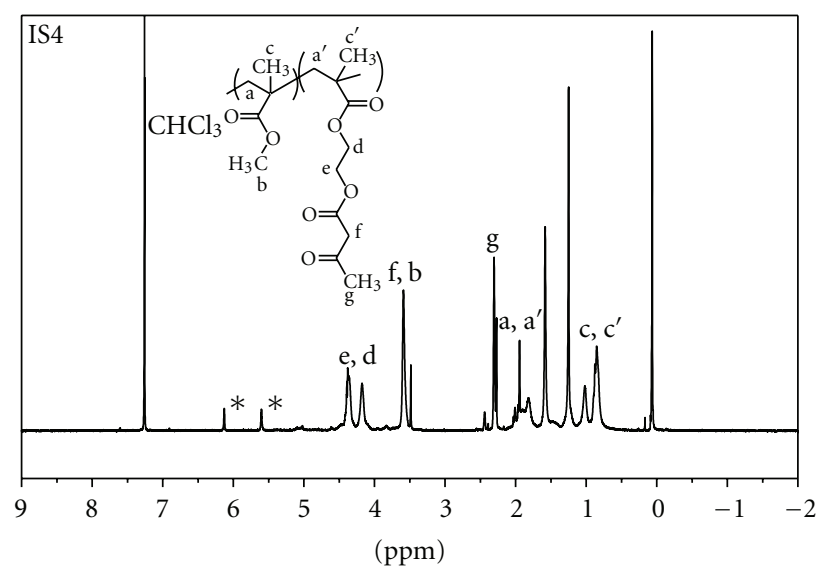

Figure 3: ${ }^{1} \mathrm{H}$ NMR spectrum of the $\mathrm{MMA}_{1.0}-$ co- $\mathrm{AEMA}_{2.2}$ random copolymer. ${ }^{*}$ Residual monomer.

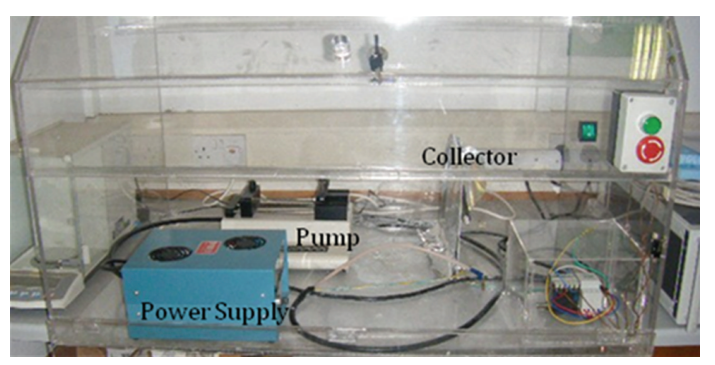

FIGURE 4: Electrospinning setup used in membrane fabrication.

\section{Results and Discussion}

3.1. Synthesis and Molecular Characterization. As already described in the experimental section, a series of MMA-coAEMA random copolymers was prepared by employing free radical polymerization.

More precisely, the synthesis of random copolymers consisting of hydrophobic methyl methacrylate (MMA) and hydrophobic metal-binding 2-(acetoacetoxy)ethyl methacrylate (AEMA) units of the type MMA-co-AEMA was performed in the presence of $2,2^{\prime}$-azobis-(isobutylnitrile) $(\mathrm{AIBN})$ that served as the radical source. Figure 1 illustrates the chemical structures and names of the monomers and initiator used for the synthesis of the MMA-co-AEMA random copolymers.

The molecular characteristics of the MMA-co-AEMA random copolymers obtained by free radical polymerization were determined by SEC and ${ }^{1} \mathrm{H}$ NMR.

Table 3 summarizes the chemical structures of the copolymers prepared in this study along with their average molecular weight (MW) and composition characteristics. As expected, the use of a noncontrolled radical polymerization process led to the generation of polymeric materials characterized by relatively high polydispersity indices (PDI) ranging between $\sim 1.8-2.6$. In Figure 2 , the SEC traces of all MMA-co-AEMA random copolymers (IS1-IS4) are displayed. 
TABLE 3: Chemical structures of the copolymers, average molecular weights, and polydispersity indices.

\begin{tabular}{|c|c|c|c|c|c|}
\hline $\mathrm{a} / \mathrm{a}$ & $\begin{array}{c}\text { Sample } \\
\text { code }\end{array}$ & Chemical structures* & $\overline{M_{n}}\left(\mathrm{~g} \cdot \mathrm{mol}^{-1}\right)$ & $\overline{M_{w}}\left(\mathrm{~g} \cdot \mathrm{mol}^{-1}\right)$ & PDI \\
\hline 1 & IS1 & $\mathrm{MMA}_{1.0}-c o-\mathrm{AEMA}_{1.0}$ & 133560 & 348740 & 2.61 \\
\hline 2 & IS2 & $\mathrm{MMA}_{1.0}-c 0-\mathrm{AEMA}_{1.07}$ & 119720 & 275890 & 2.30 \\
\hline 3 & IS3 & $\mathrm{MMA}_{1.0}-c o-\mathrm{AEMA}_{0.72}$ & 106830 & 189380 & 1.77 \\
\hline 4 & IS4 & $\mathrm{MMA}_{1.0}-c o-\mathrm{AEMA}_{2.2}$ & 104200 & 237540 & 2.28 \\
\hline
\end{tabular}

${ }^{*}$ The molar ratios between the MMA and AEMA moieties were determined by ${ }^{1} \mathrm{H}$ NMR.

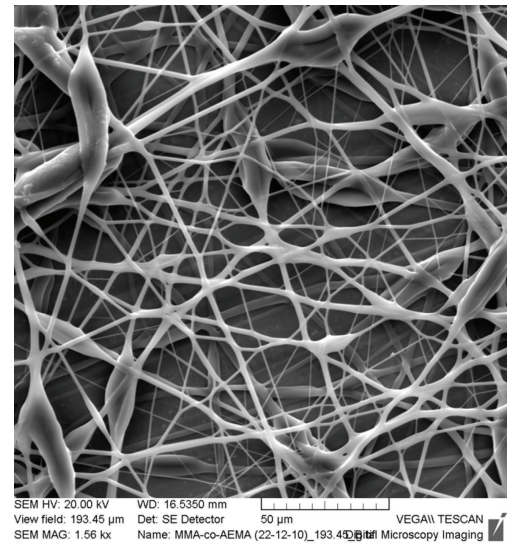

(a)

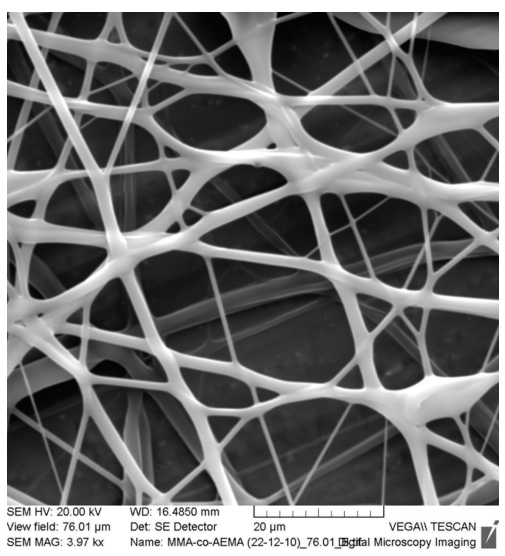

(b)

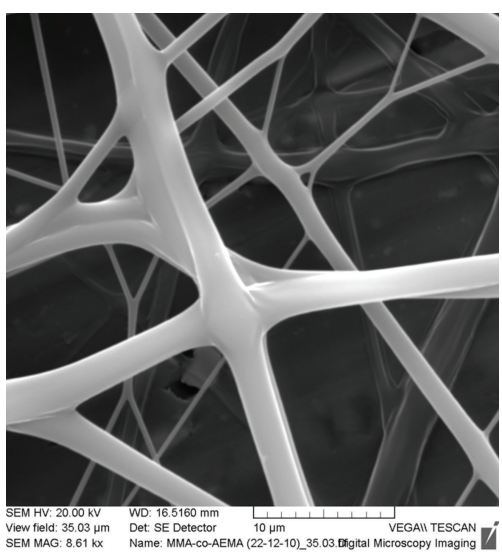

(c)

FIGURE 5: SEM images of the pristine MMA-co-AEMA polymeric membranes in the absence of $\mathrm{OA} \cdot \mathrm{Fe}_{3} \mathrm{O}_{4}$ nanoparticles.

The expected chemical structure of the MMA-co-AEMA random copolymers was confirmed by ${ }^{1} \mathrm{H}$ NMR spectroscopy. Figure 3 exemplarily shows the ${ }^{1} \mathrm{H}$ NMR spectrum of the $\mathrm{MMA}_{1.0}$-co-AEMA2.2 (IS4). The peak assignments are shown in the spectrum. The MMA:AEMA comonomer compositions (Table 3 ) were determined from the ratio of the areas under the characteristic signals of the AEMA and the MMA, appearing at $4.17\left(\mathrm{CH}_{2}, \mathrm{~d}\right)$ and $3.59\left(\mathrm{CH}_{3}, \mathrm{~b}\right)$, respectively, after subtracting from the latter the area corresponding to the $-\mathrm{CH}_{2}$ groups of $\operatorname{AEMA}(\mathrm{f})$.

\subsection{Membrane Fabrication and Morphological Characteriza-} tion. As previously mentioned, membrane fabrication was carried out via electrospinning. The electrospinning setup used in the present study is presented in Figure 4.

The success of the electrospinning process toward the production of fibrous membranes depends on various parameters such as the concentration of the polymeric solution (which significantly affects the solution viscosity), the applied voltage, the delivery rate of the solution, the diameter of the needle and the distance between the tip of the needle, and the collector.

Since this was the first work on the preparation of MMAco-AEMA polymeric membranes via electrospinning, it was necessary to carry out parametric studies in order to define the optimum experimental parameters for the production of fibrous polymer membranes in the absence of the magnetic nanoparticles, before carrying on with the incorporation of the $\mathrm{OA} \cdot \mathrm{Fe}_{3} \mathrm{O}_{4}$, for the fabrication of the magnetoactive membranes.

By employing specific experimental conditions provided in Table 2 (IS3), fibrous membranes were successfully fabricated. Figure 5 shows the SEM images of the pristine MMAco-AEMA fibers obtained in the absence of the $\mathrm{OA} \cdot \mathrm{Fe}_{3} \mathrm{O}_{4}$ nanoparticles. The fibers produced are partially separated from each other, whereas fiber bundles and junctions can be also observed. Moreover, the SEM images reveal the presence of a multimodal diameter distribution ranging between $\sim 2 \mu \mathrm{m}$ and $\sim 500 \mathrm{~nm}$. This phenomenon has been previously observed by other groups, and it has been attributed to the splitting of the electrospinning jet during the process [32].

The fabrication of magnetoactive, electrospun MMA-coAEMA-based fibrous membranes involved the incorporation of the preformed $\mathrm{OA} \cdot \mathrm{Fe}_{3} \mathrm{O}_{4}$ magnetic nanoparticles of various concentrations $(2,4$, and $10 \% \mathrm{w} / \mathrm{w})$ into polymer solutions prior to the electrospinning process. The $\mathrm{OA} \cdot \mathrm{Fe}_{3} \mathrm{O}_{4}$ nanoparticles synthesized by following the chemical coprecipitation method as described in the experimental section were characterized by TEM, which revealed the presence of many individual and some superimposed nanoparticles as reported in a recent publication [28]. Most of these particles were characterized by very small diameters of around $4-5 \mathrm{~nm}$ [28].

Upon mixing different amounts of preformed $\mathrm{OA} \cdot \mathrm{Fe}_{3} \mathrm{O}_{4}$ with the polymer in THF, homogeneous solutions containing both the magnetic nanoparticles and the polymer were obtained and were further electrospun aiming to 


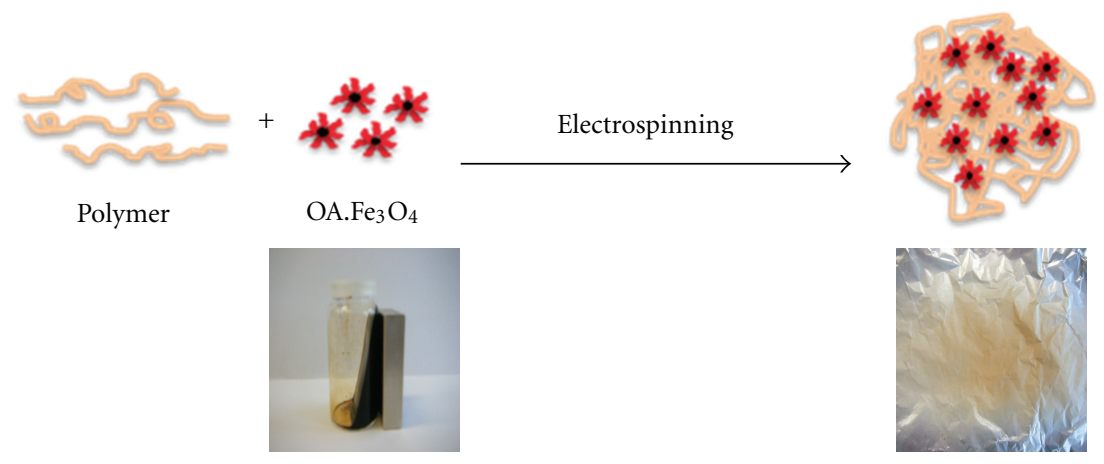

FIGURE 6: Schematic presentation of the synthetic methodology followed the fabrication of magnetoresponsive membranes. The MMA-coAEMA/OA $\cdot \mathrm{Fe}_{3} \mathrm{O}_{4}$ nanocomposite membranes were collected on an aluminum foil during the electrospinning process.

obtain magnetoactive fibrous membranes. Figure 6 is a schematic illustration of the synthetic methodology followed for the preparation of the magnetoresponsive MMA-co$\mathrm{AEMA} / \mathrm{OA} \cdot \mathrm{Fe}_{3} \mathrm{O}_{4}$ nanocomposite membranes.

The SEM images of the MMA-co-AEMA/OA $\cdot \mathrm{Fe}_{3} \mathrm{O}_{4}$ membranes, containing 2, 4 and $10 \% \mathrm{w} / \mathrm{w} \mathrm{OA} \cdot \mathrm{Fe}_{3} \mathrm{O}_{4}$ are provided in Figure 7(a), whereas MMA-co-AEMA/OA $\cdot \mathrm{Fe}_{3} \mathrm{O}_{4}$ membranes, containing higher $\mathrm{OA} \cdot \mathrm{Fe}_{3} \mathrm{O}_{4}$ percentages (30 and $70 \% \mathrm{w} / \mathrm{w}$ ) are shown in Figure 7(b).

As seen from the images, no significant changes were observed in the morphological characteristics of the fibers upon increasing the magnetic content in the range of 2$10 \% \mathrm{w} / \mathrm{w}$. Similar observations were reported by Xiaoyi et al. [25] for electrospun PVP-Fe(0) nanocomposite fibers in which the $\mathrm{Fe}(0)$ inorganic content ranged between $1.25-10 \%$ $\mathrm{w} / \mathrm{w}$. However, upon significantly increasing the magnetic content (i.e., 30 and $70 \% \mathrm{w} / \mathrm{w}$ ) while maintaining the electrospinning conditions relatively unchanged, a morphological change from fibers to bead-like structures has been induced (Figure 7(b)). A possible explanation for this morphological transition might be the influence of the $\mathrm{OA} \cdot \mathrm{Fe}_{3} \mathrm{O}_{4}$ found at high concentrations in solution on different parameters affecting the electrospinning process. According to Fong et al. [33], the formation of beads may be strongly influenced by the viscoelasticity of the solution, the charge density carried by the jet, and the surface tension of the solution. Further experimental work is required in the future involving an in-depth and systematic investigation of the effect of the magnetic content on the above-mentioned parameters so as to determine the extent at which each parameter is affected, leading to such a drastic morphological transition.

3.3. Thermal Stability. The thermal stability of the pristine and nanocomposite membranes was determined by TGA which provided the decomposition temperatures. The TGA traces of IS3 (no OA $\cdot \mathrm{Fe}_{3} \mathrm{O}_{4}$ ), IS3.4 ( $\left.4 \% \mathrm{w} / \mathrm{w} \mathrm{OA} \cdot \mathrm{Fe}_{3} \mathrm{O}_{4}\right)$, and IS3.10 $\left(10 \% \mathrm{w} / \mathrm{w} \mathrm{OA} \cdot \mathrm{Fe}_{3} \mathrm{O}_{4}\right)$ are provided in Figure 8.

As seen in the thermogram, the pristine polymer membrane begins to decompose at a slightly lower temperature $\left(\sim 200^{\circ} \mathrm{C}\right)$ compared to the nanocomposite membranes $\left(\sim 250^{\circ} \mathrm{C}\right)$, while, at $\sim 430^{\circ} \mathrm{C}$, it decomposes completely losing all of its weight. In the case of IS3.4 and IS3.10, the remaining of a residue is observed at higher temperatures $\left(T>430^{\circ} \mathrm{C}\right)$, corresponding to the $\mathrm{Fe}_{3} \mathrm{O}_{4}$ inorganic content.

3.4. Nanocrystalline Phase Characterization. The nanocrystalline phase adopted by the embedded within the nanocomposite membranes $\mathrm{OA} \cdot \mathrm{Fe}_{3} \mathrm{O}_{4}$ nanoparticles was investigated by X-ray diffraction (XRD) spectroscopy. As an example, the powder XRD diffraction pattern of the nanocomposite membrane IS3.10 is presented in Figure 9. In the same figure, the XRD of the pure $\mathrm{OA} \cdot \mathrm{Fe}_{3} \mathrm{O}_{4}$ nanoparticles is also provided for comparison. Although, in the case of IS3.10 the obtained signals are weak due to the low amount of the embedded iron oxide nanoparticles, both diffractograms display six board peaks appearing at $2 \theta \sim 30^{\circ}, 36^{\circ}, 43^{\circ}, 54^{\circ}$, $58^{\circ}$, and $63^{\circ}$, verifying the presence of magnetite $\left(\mathrm{Fe}_{3} \mathrm{O}_{4}\right)$ within the nanocomposite membranes [34-36].

3.5. Magnetic Properties. The magnetic behavior of the nanocomposite membranes was investigated by VSM at $300 \mathrm{~K}$. Figure 10 presents the magnetization versus applied magnetic field strength plots for the membranes IS3.4 and IS3.10 containing 4 and $10 \% \mathrm{w} / \mathrm{w} \mathrm{OA} \cdot \mathrm{Fe}_{3} \mathrm{O}_{4}$, respectively. The magnetic measurement studies clearly showed that these systems exhibited superparamagnetic behavior at ambient temperature, demonstrated by the symmetrical sigmoidal shape of the magnetization curves and the absence of a hysteresis loop. Moreover, from the magnetization plots it becomes obvious that, upon increasing the magnetic content within the membranes, the saturation magnetization (Ms) increases as expected, while the superparamagnetic properties are retained. It is noteworthy to mention at this point that the pristine membrane IS3 does not contribute to the magnetization, since this methacrylate-based random copolymer is a nonmagnetic coating. This also explains the fact that the IS3.4 and IS3.10 nanocomposite membranes exhibit much lower magnetization values in comparison to the Ms of the pure $\mathrm{OA} \cdot \mathrm{Fe}_{3} \mathrm{O}_{4}$ nanoparticles $(\sim 45 \mathrm{emu} / \mathrm{g})$ which is reasonable, considering the fact that the presence of a non-magnetic coating may affect the magnetization due to quenching of surface effect [37]. 

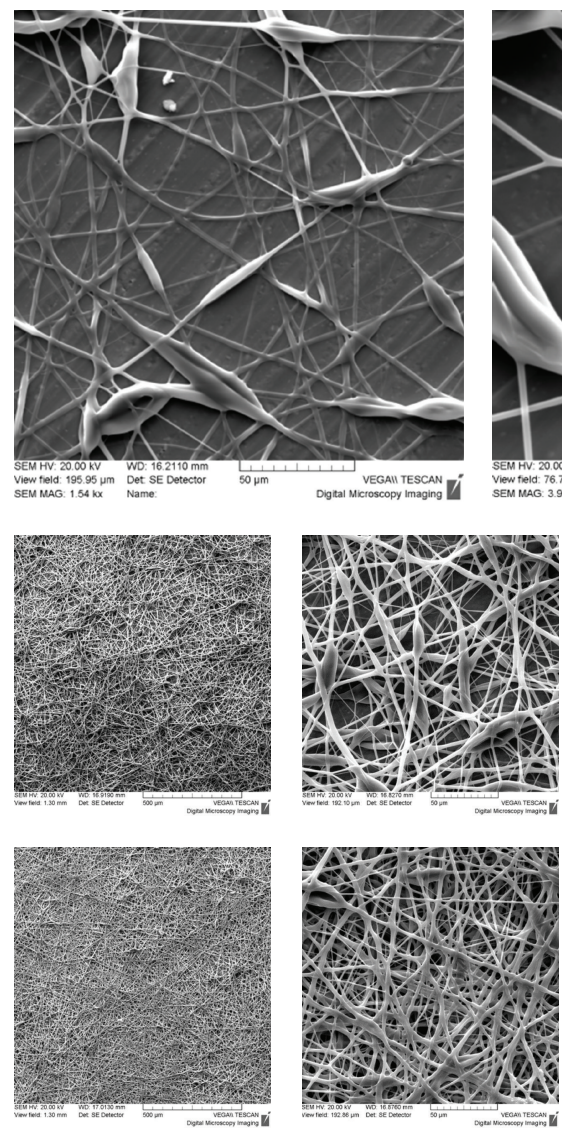
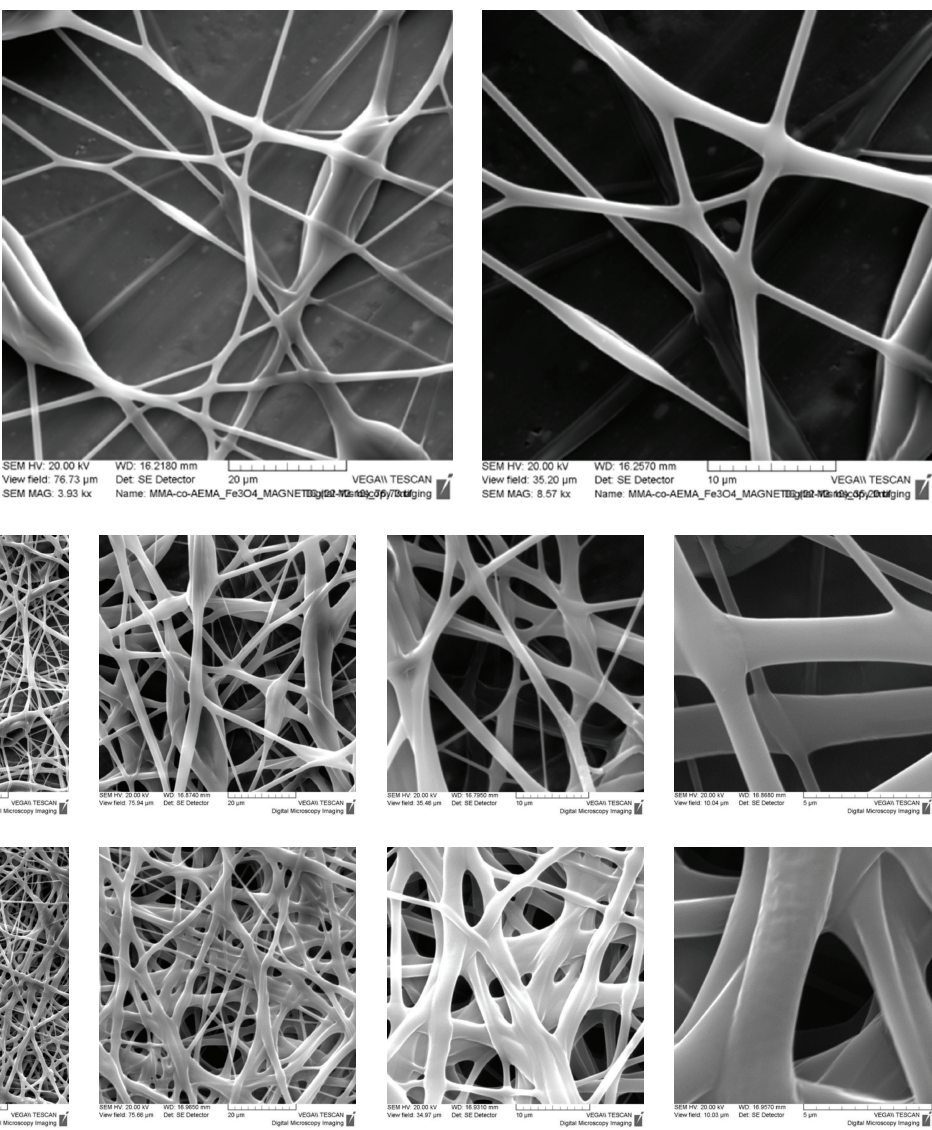

(a)
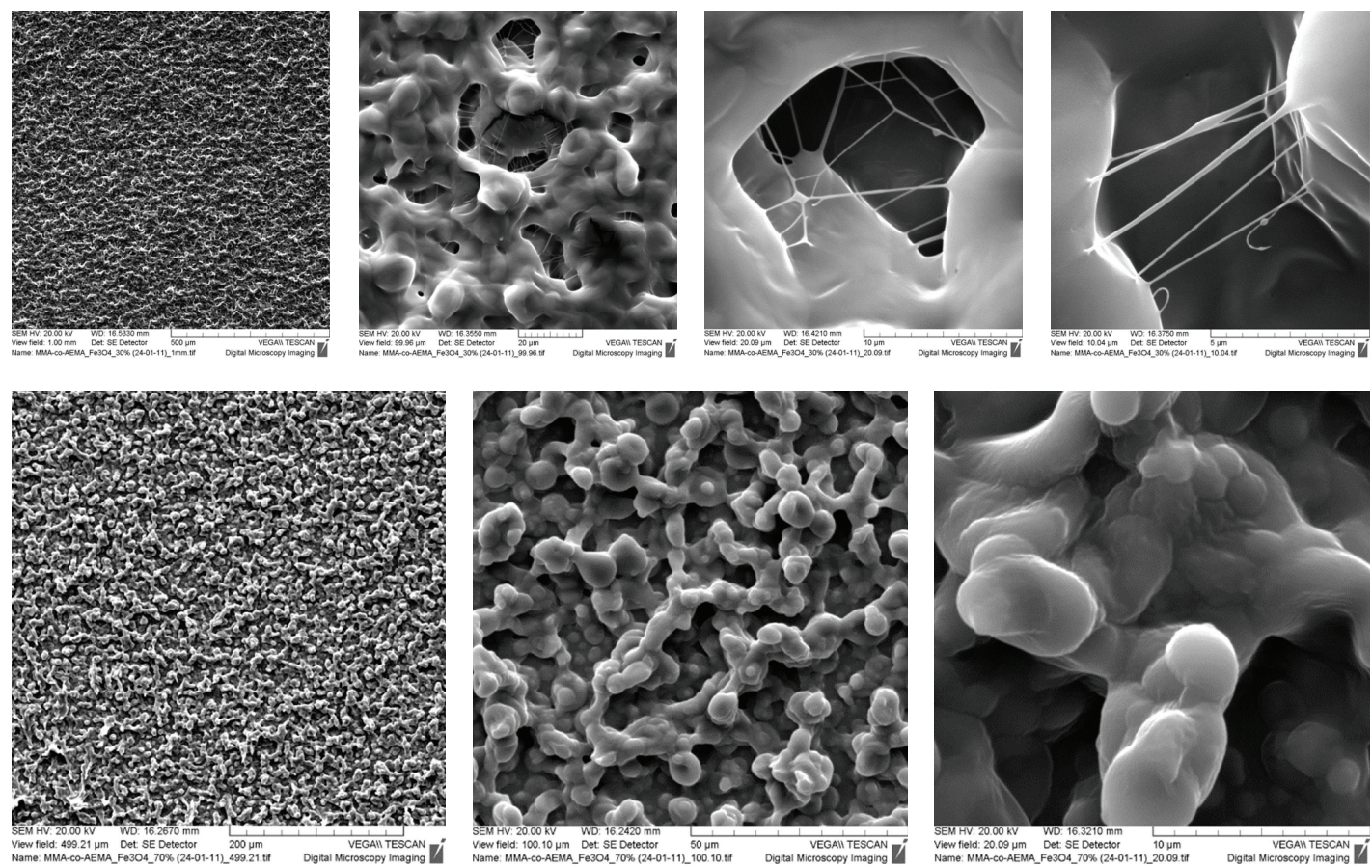

(b)

Figure 7: SEM images of the polymeric magnetoactive membranes containing (a) 2, 4, and 10\% w/w $\mathrm{OA} \cdot \mathrm{Fe}_{3} \mathrm{O}_{4}$ nanoparticles and (b) 30 and $70 \% \mathrm{w} / \mathrm{w} \mathrm{OA} \cdot \mathrm{Fe}_{3} \mathrm{O}_{4}$ nanoparticles. 


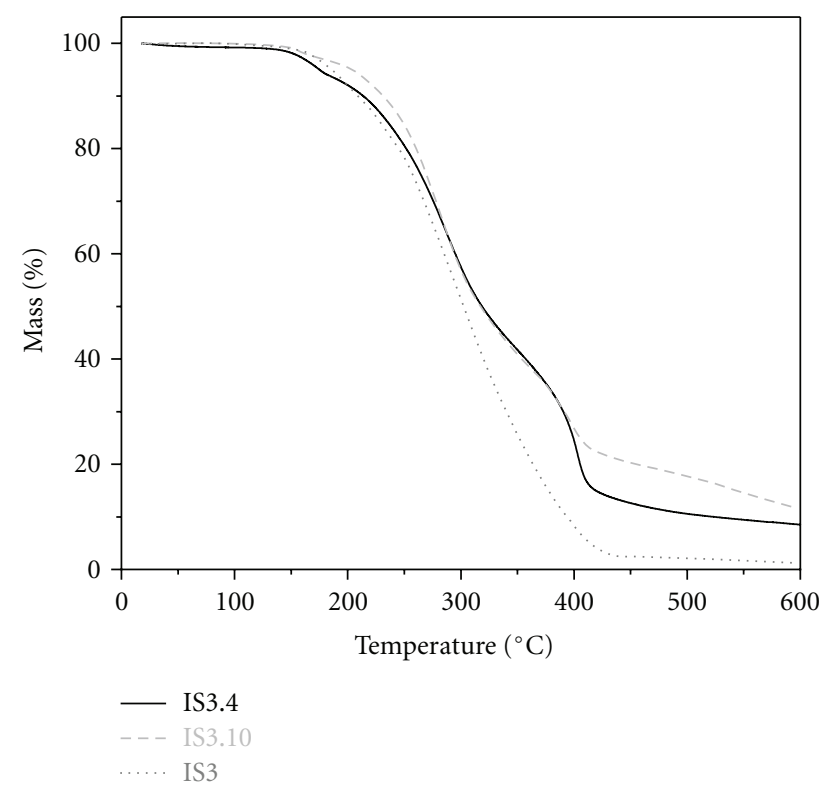

FIgure 8: TGA thermograms of IS3, IS3.4 ( $\left.4 \% \mathrm{w} / \mathrm{w} \mathrm{OA} \cdot \mathrm{Fe}_{3} \mathrm{O}_{4}\right)$, and IS3.10 $\left(10 \% \mathrm{w} / \mathrm{w} \mathrm{OA} \cdot \mathrm{Fe}_{3} \mathrm{O}_{4}\right)$.

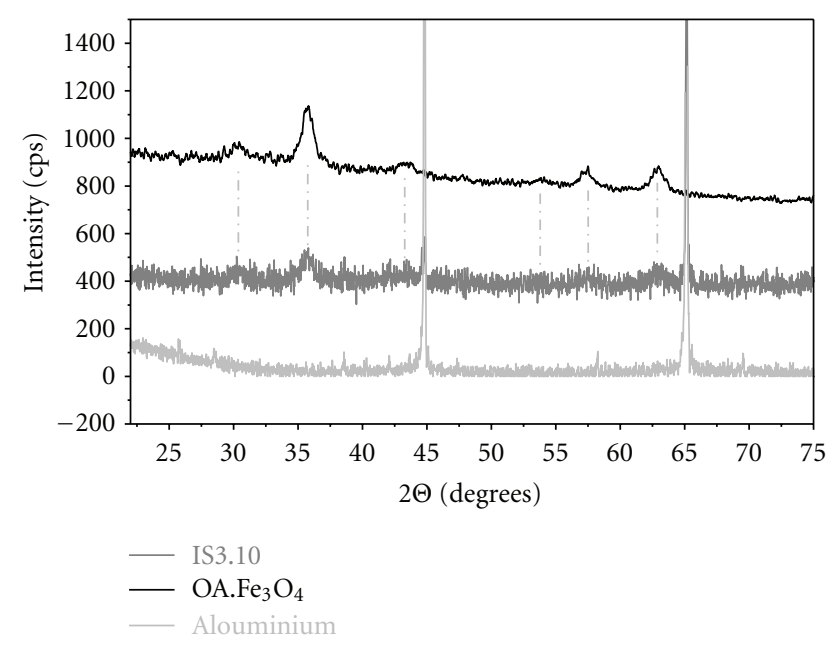

FIGURE 9: X-ray diffraction patterns of $\mathrm{OA} \cdot \mathrm{Fe}_{3} \mathrm{O}_{4}$ nanoparticles and IS3.10 $\left(10 \% \mathrm{w} / \mathrm{w} \mathrm{OA} \cdot \mathrm{Fe}_{3} \mathrm{O}_{4}\right)$ and of the aluminum foil used as a collector during the electrospinning.

\section{Conclusions}

In conclusion, the electrospinning technique has been successfully employed for the fabrication and of magnetoresponsive nanocomposite membranes consisting of MMAco-AEMA random copolymers and $\mathrm{OA} \cdot \mathrm{Fe}_{3} \mathrm{O}_{4}$ nanoparticles. Fibrous membranes with different magnetic content were produced demonstrating tunable superparamagnetic behavior. These new materials may be exploited in the near future in several applications involving magnetic fibers. Current work involves the fabrication of biocompatible and biodegradable magnetoresponsive polymer-based nanocomposite membranes destined for use in the biomedical field.

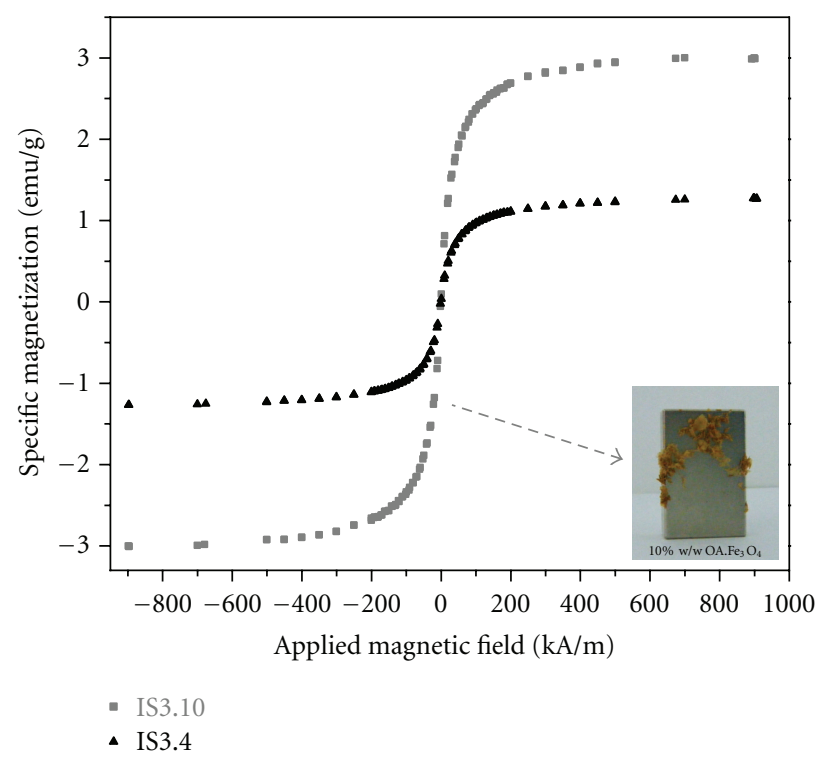

Figure 10: Magnetization curves of IS3.4 (OA. $\left.\mathrm{Fe}_{3} \mathrm{O}_{4} 4 \% \mathrm{w} / \mathrm{w}\right)$ and IS3.10 (OA $\left.\cdot \mathrm{Fe}_{3} \mathrm{O}_{4} 10 \% \mathrm{w} / \mathrm{w}\right)$ measured at $300 \mathrm{~K}$.

\section{Acknowledgment}

This work was supported by the University of Cyprus and the Center for Fundamental and Advanced Technical Research from Timisoara of the Romanian Academy. The authors are grateful to Prof Konstantinos Chrissafis (Department of Physics, Aristotle University of Thessaloniki, Greece) for the TGA measurements. The authors also thank Ms. C. Papageorgiou and Dr. T. Kyratsi (Department of Mechanical and Manufacturing Engineering, University of Cyprus) for the assistance with the XRD measurements.

\section{References}

[1] D. Wandera, S. R. Wickramasinghe, and S. M. Husson, "Stimuli-responsive membranes," Journal of Membrane Science, vol. 357, no. 1-2, pp. 6-35, 2010.

[2] H.-S. Wang, G.-D. Fu, and X. S. Li, "Functional polymeric nanofibers from electrospinning," Recent Patents on Nanotechnology, vol. 3, no. 1, pp. 21-31, 2009.

[3] A. Frenot and I. S. Chronakis, "Polymer nanofibers assembled by electrospinning," Current Opinion in Colloid and Interface Science, vol. 8, no. 1-2, pp. 64-75, 2003.

[4] R. Vasita and D. S. Katti, "Nanofibers and their applications in tissue engineering," International Journal of Nanomedicine, vol. 1, no. 1, pp. 15-30, 2006.

[5] J. Venugopal, S. Low, A. Choon, and S. Ramakrishna, "Interaction of cells and nanofiber scaffolds in tissue engineering," Journal of Biomedical Materials Research B, vol. 84, no. 1, pp. 34-48, 2008.

[6] D. Li, Y. Wang, and Y. Xia, "Electrospinning of polymeric and ceramic nanofibers as uniaxially aligned arrays," Nano Letters, vol. 3, no. 8, pp. 1167-1171, 2003.

[7] Y. Zhang, C. Teck, S. Lim, S. Ramakrishna, and Z. Huang, "Recent development of polymer nanofibers for biomedical and biotechnological applications," Journal of Materials Science, vol. 16, no. 10, pp. 933-946, 2005. 
[8] U. Metzger, P. Le-Clech, R. M. Stuetz, F. H. Frimmel, and V. Chen, "Characterisation of polymeric fouling in membrane bioreactors and the effect of different filtration modes," Journal of Membrane Science, vol. 301, no. 1-2, pp. 180-189, 2007.

[9] S. Ozdemir, M. G. Buonomenna, and E. Drioli, "Catalytic polymeric membranes: preparation and application," Applied Catalysis, vol. 307, no. 2, pp. 167-183, 2006.

[10] E. K. Lee and W. J. Koros, Membranes Synthetic Applications, vol. 9 of Encyclopedia of Physical Science and Technology, 3rd edition, 2002.

[11] M. P. Prabhakaran, L. Ghasemi-Mobarakeh, and S. Ramakrishna, "Electrospun composite nanofibers for tissue regeneration," Journal of Nanoscience and Nanotechnology, vol. 11, no. 4, pp. 3039-3057, 2011.

[12] R. Dahlin, K. F. Kurtis, and A. G. Mikos, "Polymeric nanofibers in tissue engineering," Tissue Engineering B, vol. 17, no. 5, pp. 349-364, 2011.

[13] J. Wie, S. Yan, Y. Fang et al., "Bioactive electrospun scaffolds delivering growth factors and genes for tissue engineering applications," Pharmaceutical Research, vol. 28, no. 6, pp. 1259-1272, 2011.

[14] J. Zeng, X. Xu, X. Chen, Q. Liang, and X. Bian, "Biodegratable electrospun fibers for drug delivery," Journal of Controlled Release, vol. 92, pp. 227-231, 2003.

[15] K. Graham and M. Gogins, "Incorporation of electrospun nanofibers into functional structures," Technical Assosiation of the Pulp and Paper Industry, pp. 21-27, 2004.

[16] Z. M. Huang, Y. Z. Zhang, M. Kotaki, and S. Ramakrishna, "A review on polymer nanofibers by electrospinning and their applications in nanocomposites," Composites Science and Technology, vol. 63, no. 15, pp. 2223-2253, 2003.

[17] M. Fanbin, Z. Yingqing, L. Yajie et al., "Electrospun magnetic fibrillar polyarylene ether nitriles nanocomposites reinforced with $\mathrm{Fe}$-phthalocyanine/ $\mathrm{Fe}_{3} \mathrm{O}_{4}$ hybrid microspheres," Journal of Applied Polymer Science, vol. 123, no. 3, pp. 1732-1739, 2012.

[18] W. Yan, Z. Xuehui, S. Yu et al., "Magnetic biodegradable $\mathrm{Fe}_{3} \mathrm{O}_{4} / \mathrm{CS} / \mathrm{PVA}$ nanofibrous membranes for bone regeneration," Biomedical Materials, vol. 6, no. 5, Article ID 055008, 2011.

[19] W. Biao, S. Ying, and W. Huaping, "Preparation and properties of electrospun $\mathrm{PAN} / \mathrm{Fe}_{3} \mathrm{O}_{4}$ magnetic nanofibers," Journal of Applied Polymer Science, vol. 115, no. 3, pp. 1781-1786, 2010.

[20] C. C. Zhang, X. Li, Y. Yang, and C. Wang, "Polymethylmethacrylate $/ \mathrm{Fe}_{3} \mathrm{O}_{4}$ composite nanofiber membranes with ultra-low dielectric permittivity," Applied Physics A, vol. 97, no. 2, pp. 281-285, 2009.

[21] Y. Xiang, L. Zhen-Mei, W. Z. Gang, X. J. Huang, and Z. K. Xu, "Preparation and characterization of magnetic nanofibrous composite membranes with catalytic activity," Materials Letters, vol. 63, no. 21, pp. 1810-1813, 2009.

[22] H. Wang, H. Tang, J. He, and Q. Wang, "Fabrication of aligned ferrite nanofibers by magnetic-field-assisted electrospinning coupled with oxygen plasma treatment," Materials Research Bulletin, vol. 44, no. 8, pp. 1676-1680, 2009.

[23] T. Song, Y. Zhang, T. Zhou, C. T. Lim, S. Ramakrishna, and B. Liu, "Encapsulation of self-assembled FePt magnetic nanoparticles in PCL nanofibers by coaxial electrospinning," Chemical Physics Letters, vol. 415, no. 4-6, pp. 317-322, 2005.

[24] I. H. Chen, C. C. Wang, and C. Y. Chen, "Fabrication and characterization of magnetic cobalt ferrite/polyacrylonitrile and cobalt ferrite/carbon nanofibers by electrospinning," Carbon, vol. 48, no. 3, pp. 604-611, 2010.
[25] X. Xiaoyi, W. Qiliang, C. H. Chul, and Y. H. Kim, "Encapsulation of iron nanoparticles with PVP nanofibrous membranes to maintain their catalytic activity," Journal of Membrane Science, vol. 348, no. 1-2, pp. 231-237, 2010.

[26] P. Papaphilippou, L. Loizou, N. C. Popa et al., "Superparamagnetic hybrid micelles, based on iron oxide nanoparticles and well-defined diblock copolymers possessing $\beta$-ketoester functionalities," Biomacromolecules, vol. 10, no. 9, pp. 26622671, 2009.

[27] P. C. Papaphilippou, R. Turcu, and T. Krasia-Christoforou, "Synthesis and characterization of water-dispersible, superparamagnetic single-wall carbon nanotubes decorated with iron oxide nanoparticles and well-defined chelating diblock copolymers," Journal of Polymer Science B, vol. 49, no. 19, pp. 1389-1396, 2011.

[28] P. Papaphilippou, A. Pourgouris, O. Marinica et al., "Fabrication and characterization of superparamagnetic and thermoresponsive hydrogels based on oleic-acid-coated $\mathrm{Fe}_{3} \mathrm{O}_{4}$ nanoparticles, hexa(ethylene glycol) methyl ether methacrylate and 2-(acetoacetoxy)ethyl methacrylate"', Journal of Magnetism and Magnetic Materials, vol. 323, no. 5, pp. 557-563, 2011.

[29] D. Bica, "Preparation of magnetic fluids for various applications," Romanian Reports in Physics, vol. 47, pp. 265-272, 1995.

[30] L. Vékás, D. Bica, and M. V. Avdeev, "Magnetic nanoparticles and concentrated magnetic nanofluids: synthesis, properties and some applications," China Particuology, vol. 5, no. 1-2, pp. 43-49, 2007.

[31] L. Vekas, M. V. Adveev, and D. Bica, "Magnetic nanofluids: synthesis and structure," in Nanoscience in Biomedicine, D. Shi, Ed., chapter 25, pp. 645-709, Springer, New York, NY, USA, 2009.

[32] K. Garg and G. Bowlin, "Electrospinning jets and nanofibrous structures," Biomicrofluidics, vol. 5, no. 1, Article ID 013403, 19 pages, 2011.

[33] H. Fong, I. Chun, and D. H. Reneker, "Beaded nanofibers formed during electrospinning," Polymer, vol. 40, no. 16, pp. 4585-4592, 1999.

[34] T. Gong, D. Yang, J. Hu, W. Yang, C. Wang, and J. Q. Lu, "Preparation of monodispersed hybrid nanospheres with high magnetite content from uniform $\mathrm{Fe}_{3} \mathrm{O}_{4}$ clusters," Colloids and Surfaces A, vol. 339, no. 1-3, pp. 232-239, 2009.

[35] S. Wan, J. Huang, H. Yan, and K. Liu, "Size-controlled preparation of magnetite nanoparticles in the presence of graft copolymers," Journal of Materials Chemistry, vol. 16, no. 3, pp. 298-303, 2006.

[36] W. Jingjing and L. Dengxin, "Preparation and characterization of magnetic $\mathrm{Fe}_{3} \mathrm{O}_{4}$ Nanoparticles coated by oleic acid," Energy Procedia, vol. 11, pp. 4794-4802, 2006.

[37] C. Yee, G. Kataby, A. Ulman et al., "Self-assembled monolayers of alkanesulfonic and -phosphonic acids on amorphous iron oxide nanoparticles," Langmuir, vol. 15, no. 21, pp. 7111-7115, 1999. 

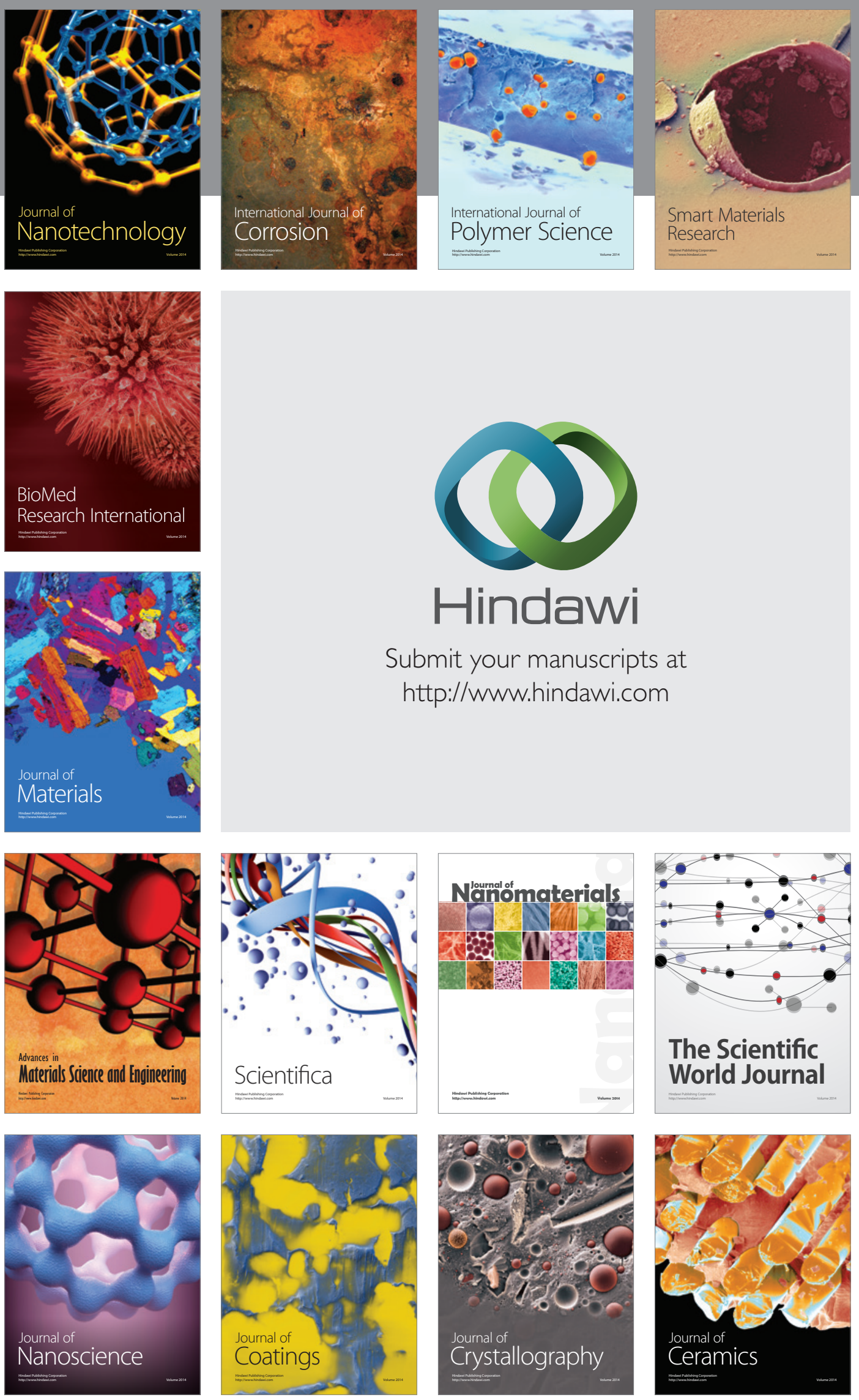

The Scientific World Journal

Submit your manuscripts at

http://www.hindawi.com

\section{World Journal}

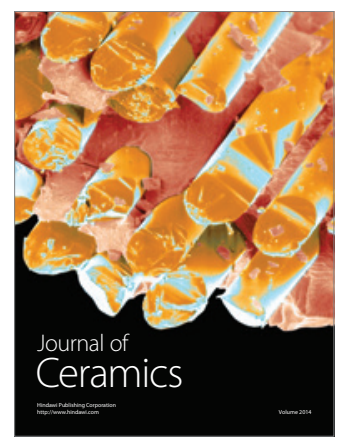

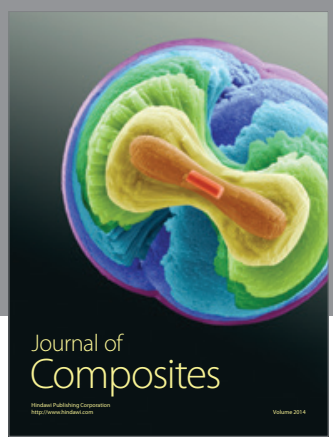
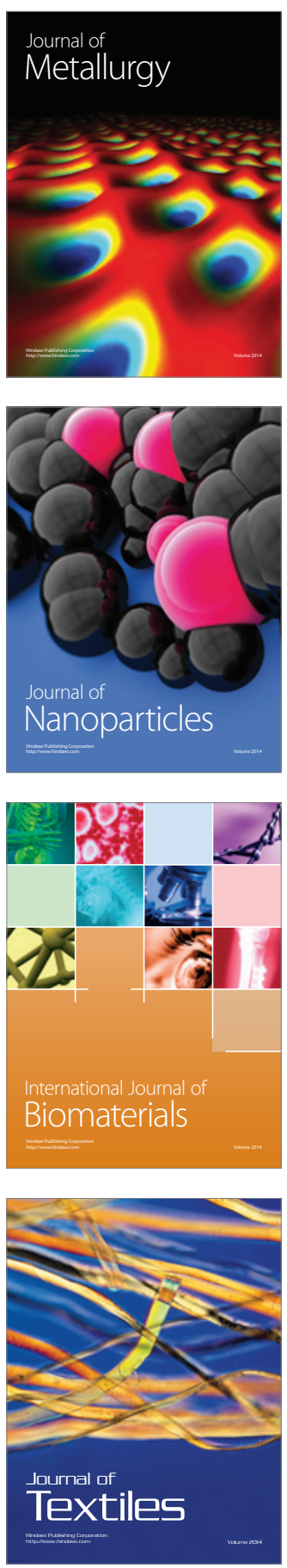